\title{
Effect of Sintering on Hydroxyapatite/Sodium Alginate Properties
}

\section{Nanthini Kanasan ${ }^{1}$, Sharifah Adzila ${ }^{1}$, Nor Azimah Mustaffa ${ }^{1}$, Mohd. Nasrull Abdol Rahman ${ }^{1}$, Mohd.Fahrul Hassan ${ }^{1}$, Gurubaran Panerselvan ${ }^{2}$}

\author{
${ }^{1}$ Faculty of Mechanical and Manufacturing Engineering, Universiti Tun Hussein Onn Malaysia, 86400 Batu Pahat, \\ Johor, Malaysia, \\ ${ }^{2}$ School of Mechatronic Engineering, Universiti Malaysia Perlis, Pauh Putra Campus, Arau, Perlis, Malaysia,
}

Received 7 January 2018; accepted 23 January 2018, available online 3 July 2018

\begin{abstract}
In the present work, a precipitation method was used to prepare a nanocomposite powders consisting of hydroxyapatite and sodium alginate by varying the composition of sodium alginate. The characterization of powder are analyzed by using Field Emission Scanning Electron Microscopy (FESEM) and X-ray diffraction (XRD). FESEM is used to identify the morphology and agglomeration of sintered samples while, XRD analysis is used to identify the phase of samples with an increase in the composition of sodium alginate up to $10 \%$. Green samples were prepared and sintered at temperature $1000^{\circ} \mathrm{C}$ and $1100^{\circ} \mathrm{C}$ and the sintered samples are studied based on their phase stability, density and Vickers hardness. The result indicates that there is no secondary phase change happen in this XRD result. The density of $\mathrm{HA} / \mathrm{SA}$ are increasing relative to hardness for composition ratio $99.5 / 0.5 \%$. The maximum density were attained by $99.5 / 0.5 \%(\mathrm{HA} / \mathrm{SA})$ at $2.12 \mathrm{~g} / \mathrm{cm}^{3}$ and $2.16 \mathrm{~g} / \mathrm{cm}^{3}$ for $1000^{\circ} \mathrm{C}$ and $1100^{\circ} \mathrm{C}$ respectively while, the maximum hardness were also attained by $99.5 / 0.5 \%$ for temperature $1000^{\circ} \mathrm{C}$ and $1100^{\circ} \mathrm{C}$ at $0.53 \mathrm{GPa}$ and $0.62 \mathrm{GPa}$ respectively. FESEM images of pure hydroxyapatite are fully dispersed in sodium alginate and the particles size are in agglomerate conditions. The aims of this research is to identify the effect of sintering on physical and mechanical properties of HA/SA.
\end{abstract}

Keywords: Hydroxyapatite, Sodium alginate, Vickers hardness, Agglomerate, Sintering

\section{Introduction}

Bioactive ceramic such as hydroxyapatite are suitable to be used for hard tissues replacement. Hydroxyapatite is mainly composed in human body. Hydroxyapatite (HA) $\left(\mathrm{Ca}_{10}\left(\mathrm{PO}_{4}\right)_{6}(\mathrm{OH})_{2}\right.$ is the inorganic component of bones that have excellent biocompatibility and widely used for implant material in non-load bearing areas of the body. It is widely used in medical application such as orthopedics and dentistry. However, it has limited use in load bearing applications due to its low strength and brittle [1-5].

In order to improve the physical and mechanical properties of hydroxyapatite, sodium alginate is used to be mixed with hydroxyapatite. Alginate (Alg) is a natural polymer synthesis from brown algae and it is more prefer due to it characteristic which is non-toxic, biocompatibility and low cost. Alginate can act as a gelling properties as it cross-linking with the divalent cations. Due to the characteristic, it have been used as entrapping matrix such as drug delivery and in surgical field. Alginate are widely used in therapeutics, tissues engineering, phaemaceuticals and etc [6-9]. Based on the previous studies, there is only a few researchers have investigate on HA/SA nanocomposites. In this research, sodium alginate is used as a binder for compaction

*Corresponding author: adzila@uthm.edu.my

2011 UTHM Publisher. All right reserved.

penerbit.uthm.edu.my/ojs/index.php/ijie process and as a sintering aids in HA/SA. Hydroxyapatite/ sodium alginate (HA/SA) composite are

one of the alternative that are promising in biomedical applications in term of improvement in physical and mechanical properties [9-12].HA are crosslink with natural polymer to produce a composite materials due to it better biocompatibility and biodegradability. The ability of alginate to form gels in the presence of calcium ions on hydroxyapatite make improvement in biomaterial for implant applications [12-14].

HA/SA composites are prepared by using precipitation method. Precipitation method are commonly used due to the simplicity of materials to be operated. Other than that, this method can decrease the contamination of powder and produce the high homogeneous purity of powders [3]. Many researchers reported that the sintering process are important in improving based on physical and mechanical properties of HA. In this research, the sintering temperature are varied from $1000^{\circ} \mathrm{C}$ and $1100^{\circ} \mathrm{C}$. Sintering temperature are important factors which could affect the strength of HA and SA. Sintering have a tendency to eliminated the functional groups of $\mathrm{OH}$ in the HA [3].

The aims of this study are to prepare HA/SA composites with various ratio and to determine the function of SA in physical and mechanical properties of HA. The 
microstructure and properties of HA/SA prepared powders are evaluated based on varying two different sintering temperatures.

\section{Experimental Method}

The commercial HA nano powder $\mathrm{Ca}_{10}\left(\mathrm{PO}_{4}\right)_{6}(\mathrm{OH})_{2}$ (Emory,99.5\%) and sodium alginate $\mathrm{NaC}_{6} \mathrm{H}_{7} \mathrm{O}$ were obtained from Sigma Aldrich. The samples ratio are $100 / 0 \%, 99.5 / 0.5 \%, 97 / 3 \%, 95 / 5 \%, 92 / 8 \%$ and $90 / 10 \%$ (HA/SA). The HA/SA was prepared by using precipitation method and subsequently left overnight for 24 hours. The powders suspension was dried at $80^{\circ} \mathrm{C}$ for 24 hours. Next, the powders were sieved and crushed by using mortar pestle and were compacted at $19.9 \mathrm{MPa}$ uniaxial pressed machine. The compacted samples at two different temperatures at $1000^{\circ} \mathrm{C}$ and $1100^{\circ} \mathrm{C}$ in 2 hours with $2^{\circ} \mathrm{C} / \mathrm{min}$ of heating and cooling rates. All the prepared powders were characterized by XRD (Bruker D8 Advanced X-ray diffractometer) and Field Emission Scanning Electron Microscopy (JSM model JEOL, Japan). FESEM was used to evaluate the powder morphology. The density of sintered samples was determined by using Archimedes principle (Mettler Toledo Densitometer). The compacted samples are grind and polished by using silicon carbide papers (grade 40007000) and diamond paste to do the final polishing. The sample surface is coated with gold before microstructure analysis are characterized under FESEM. The Vickers hardness of HA/SA are measured by using pyramidal diamond indenter (HMV,Shimadzu) hardness tester. The indentations were performed on the grinded and polished samples at $0.2 \mathrm{HV}$ with an indentation time of $10 \mathrm{~s}$. The hardness of the sintered HA/SA samples were carried out by using an optical microscope.

\section{Results and Discussion}

\subsection{Characterization of powder}

XRD pattern of HA/SA samples sintered at $0^{\circ} \mathrm{C}$, $1000^{\circ} \mathrm{C}$ and $1100^{\circ} \mathrm{C}$ are presented in Figure $1(\mathrm{a}), 1(\mathrm{~b})$ and 1(c). XRD of sintered samples shows that there is no phase transformation or decomposition of samples when sintered at different sintering temperatures. All peaks are matched with the JCPDS No. 09-0432 for hydroxyapatite. Figure 1a shows the XRD pattern of HA/SA of unsinter samples with high intensity and broad peaks.

While, Figure 1(b) and 1(c) shows the peaks intensity of HA/SA are decreased at both sintering temperatures. This is due to the effect from the formation of nonstoichiometric phase caused by dehydroxylation behavior of HA and shows the similar result with Zhou et al. 2015 [12]. All the observed peaks are compared with JCPDS file No. 09-0432 for hydroxyapatite and there are no obvious secondary peaks that exist such as tricalcium phosphate in the XRD result which indicated the purity of the samples. The intensity of HA/SA in XRD peaks and the sintering temperature played an important role in phase formation of hydroxyapatite. The less composition of SA enhances the formation of crystalline while higher composition of SA leads to crystallinity of samples. The higher sintering temperature leads to high crystallinity of samples. Based on the observation of XRD pattern, there is no noticeable of increased in intensity peaks with the sintering temperature. S. Ramesh et al., 2013 [11]; Wang et al., 1998 [13] discussed that the temperature $>1400^{\circ} \mathrm{C}$ will lead to decomposition of HA/SA which change the phase to $\beta$-TCP and $\alpha$-TCP.

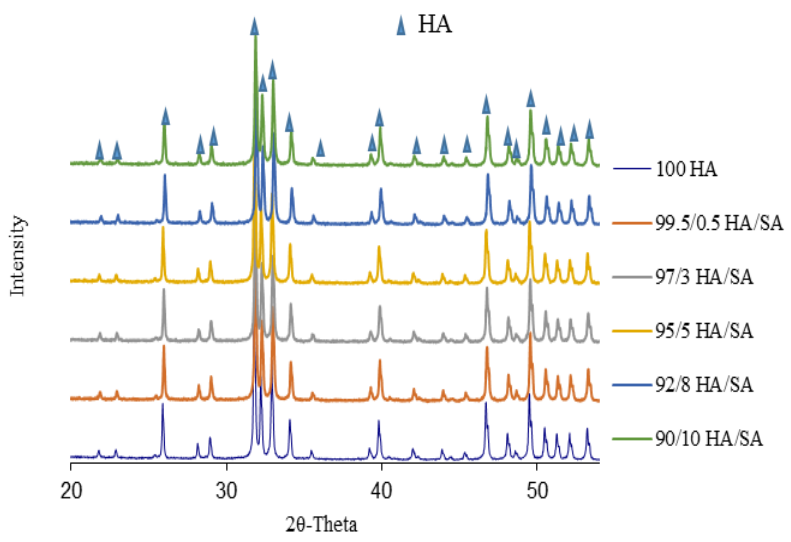

Figure 1 (a): XRD pattern of HA/SA samples at $0^{\circ} \mathrm{C}$

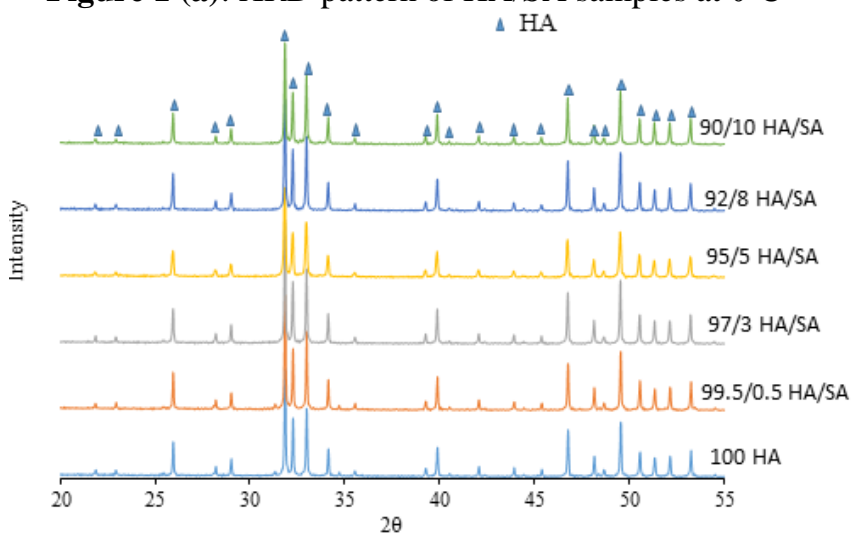

Figure 1 (b): XRD pattern of HA/SA of sintered samples at $1000^{\circ} \mathrm{C}$

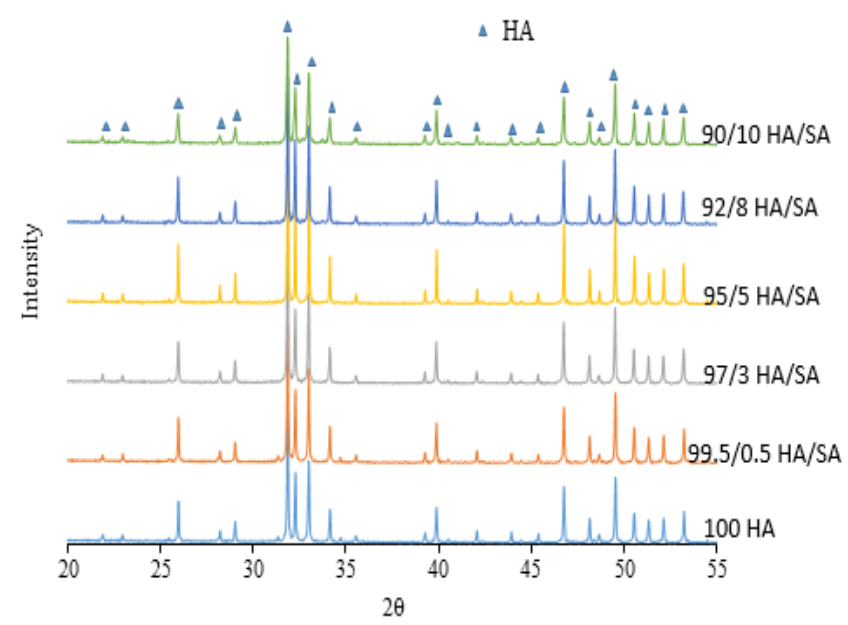

Figure 1 (c): XRD pattern of HA/SA of sintered samples at $1100^{\circ} \mathrm{C}$

\subsection{Microstructure Analysis}

Field Emission Scanning Electron Microscopy (FESEM) of sintered samples at $1000^{\circ} \mathrm{C}$ and $1100^{\circ} \mathrm{C}$ for 
both temperatures are shown in Figure 2(a) and 2(b). FESEM microstructure reveals that the prepared samples consist of agglomerates particles that cannot be identified by individually and it is in irregular shapes. These agglomerates particles appeared to be more compact, dense and irregular shapes with various sizes resulting to a rougher surface. FESEM analysis of sintered samples shows the presence of pores. The microstructure of $\mathrm{HA} / \mathrm{SA}$ at $1000^{\circ} \mathrm{C}$ shows the interconnected pore appears in $\mathrm{HA}$, while for $1100^{\circ} \mathrm{C}$, the pores decrease with the increase of sintering temperature. The increase in sintering temperature has reduced the porosity and increase the particles size of HA and SA. HA particles were fully disbursed through the SA resulting the complete composite materials. It cannot be identified individually due to fully covered of sodium alginate into HA particles. This is similar to Rajkumar et al., 2011 [12], said that this is due to the interaction between the hydroxyl and carboxyl from HA and SA. There is the strong interaction between the alginate and carbonate content between sodium alginate and hydroxyapatite which resulting to composite materials and this study is similar to Choi and Kumta, 2006 [1].

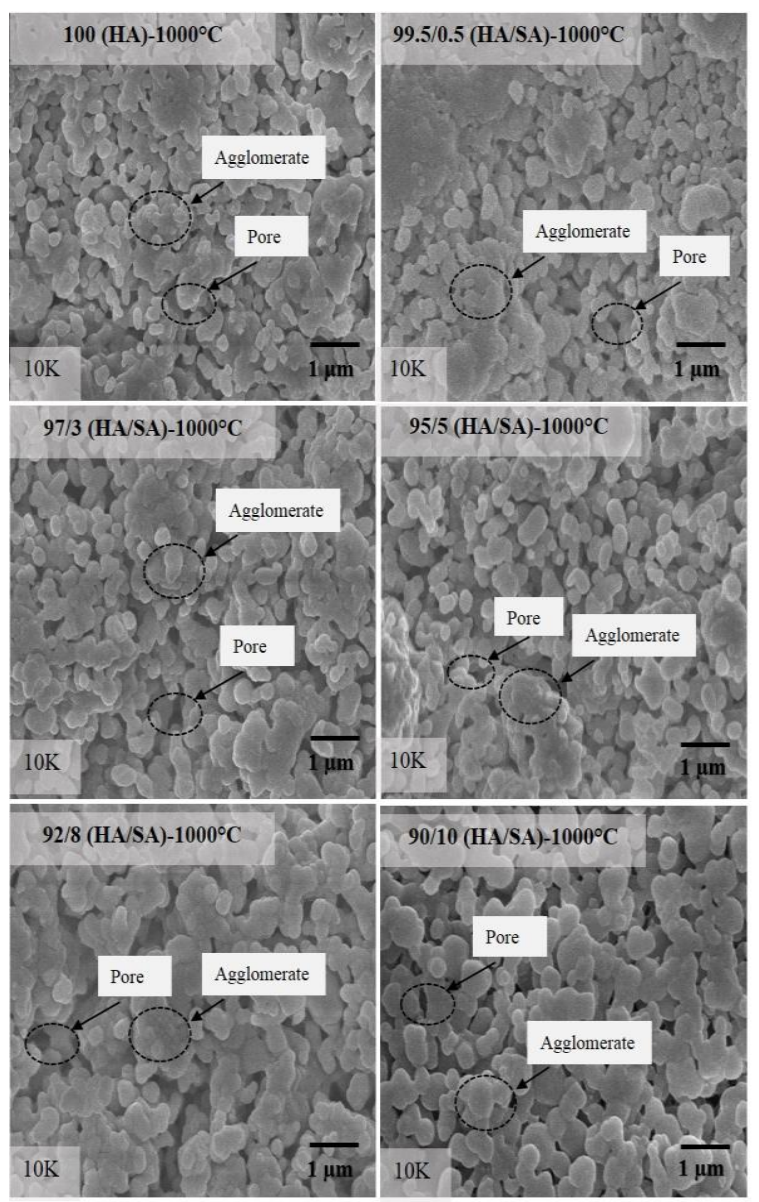

Figure 2(a): The microstructure of HA and HA/SA sintered samples at $1000^{\circ} \mathrm{C}$
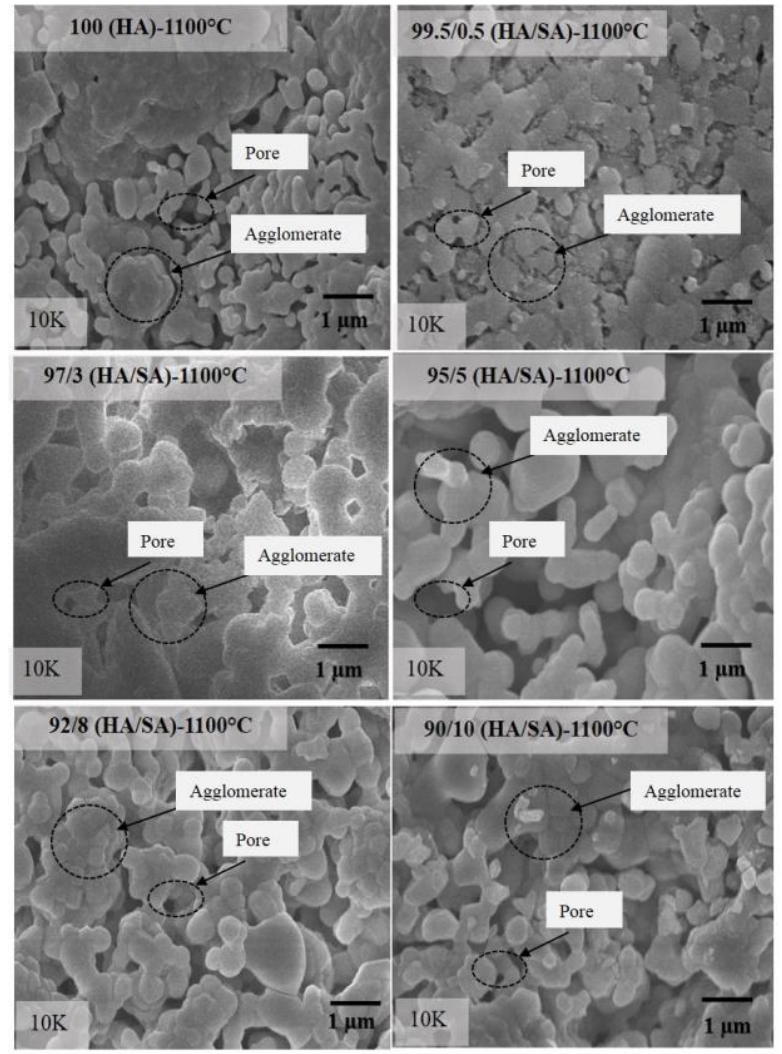

Figure 2(b): The microstructure of HA and HA/SA sintered samples at $1100^{\circ} \mathrm{C}$

The rapid growth of particles size was observed in Figure 2(a) and 2(b) for $1000^{\circ} \mathrm{C}$ to $1100^{\circ} \mathrm{C}$. Results confirmed that, the interconnected pores and the rougher surface will promote regeneration of bones [12]. HA/SA samples sintered at temperature $1100^{\circ} \mathrm{C}$, shows that the microstructure have better wettability and provide rougher surface with low porosity. Figure 2 (c) and 2(d) shows the EDS data of HA, SA and HA/SA.
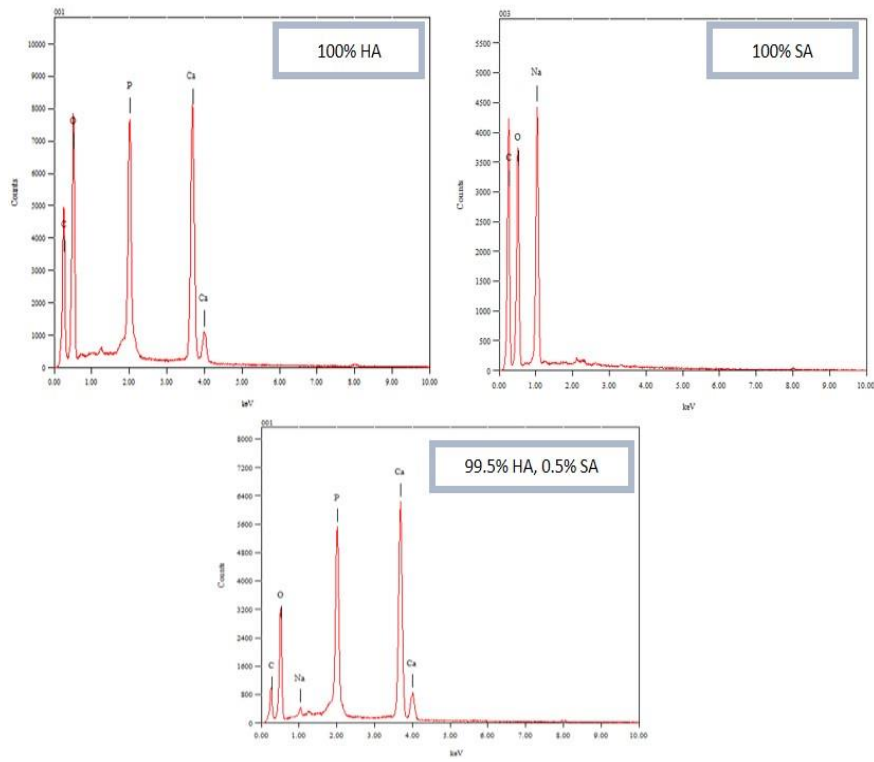

Figure 2(c): The EDS analysis of HA, SA and HA/SA 


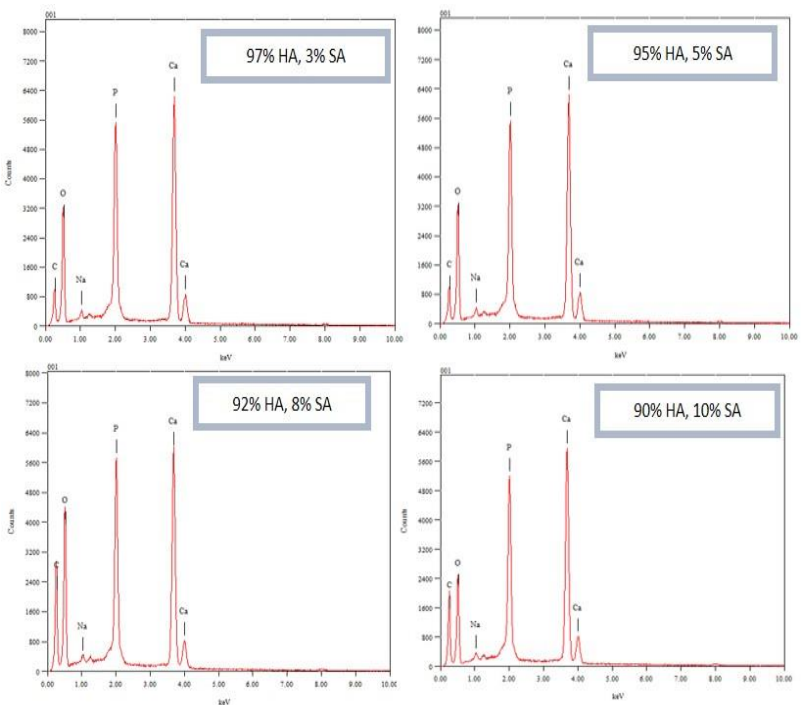

Figure 2(d): The EDS analysis of HA/SA at various composition

The Energy-dispersive spectroscopy (EDS) were used to identify the elements that presence in the morphology samples. The EDS analysis shows that there is the presence of $\mathrm{Ca}, \mathrm{P}, \mathrm{C}$ and $\mathrm{O}$ in hydroxyapatite prepared samples while in sodium alginate there is the presence of $\mathrm{Na}, \mathrm{C}$ and $\mathrm{O}$. The combination of hydroxyapatite (HA)/sodium alginate (SA) powder shows that the EDS analysis shows there is the presence of $\mathrm{Ca}, \mathrm{P}, \mathrm{Na}, \mathrm{C}$ and $\mathrm{O}$ in all composition samples. It have been proved that the sodium alginate still exist and dispersed in HA.

\subsection{Physical and Mechanical Testing}

The effect of sintering temperature on Vickers hardness is shown in Figure 3. The density and hardness data are relative at $99.5 / 0.5 \% \mathrm{HA} / \mathrm{SA}$ for sintering temperature at $1000^{\circ} \mathrm{C}$ and $1100^{\circ} \mathrm{C}$. The relative density are increased from $2.12 \mathrm{~g} / \mathrm{cm}^{3}$ at $1000^{\circ} \mathrm{C}$ to $2.16 \mathrm{~g} / \mathrm{cm}^{3}$ at $1100^{\circ} \mathrm{C}$. The increase in density is clearly shown that there is some improvement in term of increasing the sintering temperature up to $1100^{\circ} \mathrm{C}$ as shown in Figure 3 . There is the decrease in density at ratio $97 / 3 \%, 95 / 5 \%$, $92 / 8 \%$ and $90 / 10 \%$ which due to the effect of porosities. The sintering temperature have a crucial effect on the densification process in term of grain size, particles size, pore size, density and mechanical properties of sintered samples. These studies are similar to Naruporn $\mathbf{M}$ \& Chokchai Y, 2010 [3]. The hardness and densification at $100 / 0 \%$ to $99.5 / 0.5 \%$ are increase with grain size and reach the maximum value. Therefore, the hardness starts to decrease at ratio $97 / 3 \%, 95 / 5 \%, 92 / 8 \%$ and $90 / 10 \%$ due to the effect of porosities and particles bonding. This result is similar to Ramesh et al., 2013 [11] which said that the decrease in hardness is due to the effect of grain size. In general, both results for hardness and density resemble very close to each other at a sintering temperature of $1000^{\circ} \mathrm{C}$ and $1100^{\circ} \mathrm{C} .99 .5 / 0.5 \%$ shows the point where maximum densification and hardness take place. It is noted that, the densification is occurred after
$0.5 \%$ of sodium alginate was added into hydroxyapatite powder. The addition of sodium alginate up to $0.5 \%$ decreases the densification and hardness of samples. It can prove by Rajkumar et al., 2011 [12]. The maximum hardness is observed at $99.5 / 0.5 \%(\mathrm{HA} / \mathrm{SA})$ with $0.53 \mathrm{GPa}$ and $0.62 \mathrm{GPa}$ for $1000^{\circ} \mathrm{C}$ and $1100^{\circ} \mathrm{C}$ respectively. The sintering temperatures have influenced the hardness of the sample where the higher sintering temperature can lead the particles to be closely packed to form a dense materials. It can be predict that the less sodium alginate composition are denser and affect the hardness to increase due to sintering process.

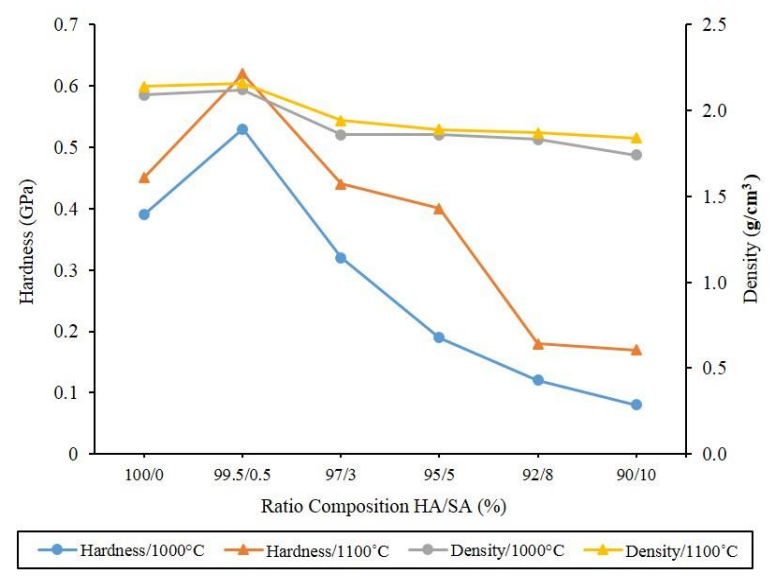

Figure 3: Hardness (GPa) versus ratio composition of pure $\mathrm{HA}$ and $\mathrm{HA} / \mathrm{SA}$

\section{Summary}

In this study, HA composite with various percentages of sodium alginate were prepared by using precipitation method. The composite formation, morphology, densification and hardness are study with respect to SA composition. The phase and intermolecular reaction between HA and SA were studied by using XRD and FESEM analyses. The characterization of HA/SA composite after sintering process indicates that the sintering temperature has a significant effect on the microstructure, densification and hardness of samples. $\mathrm{HA} / \mathrm{SA}$ sintered at below than $1100^{\circ} \mathrm{C}$ showed the rougher surface with the presence of pores between the particles. The analyses showed that, the particles size of HA are difficult to identify individually due to the addition of SA composition. This is due to the effect of alginate that fully disbursed in the hydroxyapatite samples. The addition of small amounts of sodium alginate can influence the XRD phase of HA and HA/SA samples. Furthermore, according to the FESEM images, the particles shapes of HA are depend on the amount of sodium alginate added. The morphology of HA/SA are agglomerate and in irregular shape. While the density and hardness are higher observed at $99.5 / 0.5 \%$ with $2.16 \mathrm{~g} / \mathrm{cm}^{3}$ and $0.62 \mathrm{GPa}$ due to less composition of sodium alginate for $1100^{\circ} \mathrm{C}$ each respectively. It can be summaries that, the sintering temperatures effect the 
hardness of sample which lead the particle to be closely packed to form a dense materials.

\section{Acknowledgement}

The authors gratefully acknowledge the Office for Research, Innovation, Commercialization and Consultancy Management (ORICC), Universiti Tun Hussein Onn Malaysia (UTHM) and Centre Graduate of Study (CGS).This paper was partly sponsored by Center for Graduate Studies.

\section{References}

[1] Choi, D., \& Kumta, P. N. An Alternative Chemical Route for the Synthesis and Thermal Stability of Chemically Enriched Hydroxyapatite. Journal of the American Ceramic Society, Volume 89, (2006), pp.44449.

[2] Aminzare, M., Eskandari, A., Baroonian, M., Berenov, A., Hesabi, Z. R., Taheri, M., \& Sadrnezhaad, S. Hydroxyapatite nanocomposites: Synthesis, sintering and mechanical properties. Ceramics International, Volume 39, (2013), pp. 2197-2206.

[3] Naruporn, M., and Chokchai, Y. Effect of Sintering on Microstructure and properties of Hydroxyapatite Produced by Different Synthesizing Methods. Journal of Metal, Materials and Minerals, Volume 20, (2010), pp.53-61.

[4] Seok, H., Lee, S., Kim, S., Seo, D., Kim, H. S., Kweon, H. Y.,Chae, W. The Effect of Silk Membrane Plus 3\% 4-hexylresorcinol on Guided Bone Regeneration in a Rabbit Calvarial Defect Model. International Journal of Industrial Entomology, Volume 27, (2013), pp. 209-217.

[5] Seok, H., Young Jo, Y., Kweon, H., Baek, D., \& Kim, S. Comparative study on bone regeneration between silk mat incorporated 4hexylresorcinol and collagen membrane. International Journal of Industrial Entomology, Volume 34, (2017), pp.32-37.

[6] Nanthini, K., Adzila, S., Suid, M. S. \& Panerselvan, G. Preparation and Characterization of Hydroxyapatite / Sodium Alginate Biocomposites for Bone Implant Application. AIP Proceedings, Volume 1756, (2016) ,pp. 5162-5165.
[7] Nanthini, K., Adzila, S., Azimah, M.N., Gurubaran.P. The Effect of Sodium Alginate on the Properties of Hydroxyapatite. Procedia Engineering, Volume 184, (2017), pp. 442 448.

[8] Adzila, S., Kanasan, N., Hassan M, F., A. Mubarak, Yunos M, Z., Nasrull M., and R, Haq. Synthesis And Characterization Of Magnesium Doped Calcium Phosphate for Bone Implant Application. ARPN Journal, Volume 11,( 2016), pp. 8694-8697.

[9] Koutsopoulos, S., and Dalas, E. The Crystallization of Hydroxyapatite in the Presence of Lysine. Journal of Colloid and Interface Science, Volume 231, (2000), pp. 207-212.

[10] Muralithran, G., and Ramesh, S., The Effects of Sintering Temperature on the Properties of Hydroxyapatite. Ceramic. International, Volume 26,(2000), pp. 221-30.

[11] Ramesh, S., Adzila, S., Tan, C.Y., Purbolaksono, J., Noor A, M., Hassan M, A., Sopyan ,I., and Teng, W. D. Properties of hydroxyapatite synthesize by wet chemical method. Journal of Ceramic Processing Research, Volume 14, (2013), pp. 448-452.

[12] Rajkumar, M., Meenakshisundaram, N., and Rajendran, V. Development of Nanocomposites Based on Hydroxyapatite/sodium Alginate: Synthesis and Characterisation. Materials Characterization, Volume 62, (2011), pp.469.

[13] Wang, C.K., Ju, C.P.\& Lin, J.H.C. Effect of doped bioactive glass on structure and properties of sintered hydroxyapatite. Materials Chemistry and Physics, Volume 53,(1998), pp.138-149.

[14] Zhou, K., Zhang, X., Chen, Z., Shi, L., and Li, W. Preparation and characterization of hydroxyapatite-sodium alginate scaffolds by extrusion freeforming. Ceramic. International., Volume 41,(2015), pp. 14029-14034. 